\title{
Study on difference of peripheral serum SP-D, anti-MDA5, IL-6 and TNF- $\alpha$ in CTD-ILD patients.
}

\author{
Junli Wang ${ }^{\# \#, ~ Y a n s h e n g ~ W a n g ~}{ }^{2 \#}$, Bing $\mathrm{Han}^{3}$, Jian $\mathrm{Xu}^{3}$, Xiaoli $\mathrm{Li}^{4}$, Yan Rong${ }^{4}$, Dandan Zhang ${ }^{*}$ \\ ${ }^{1}$ Doctor Attending Physician, Department of Respiration, Shenzhen Hospital, Southern Medical University, Shenzhen, \\ Guangdong, PR China \\ ${ }^{2}$ State Key Laboratory of Respiratory Disease, Guangzhou Institute of Respiratory Health, the First Affiliated Hospital \\ of Guangzhou Medical University, Guangzhou, Guangdong, PR China \\ ${ }^{3}$ Doctor Associate Chief Physician, Department of Respiration, Shenzhen Hospital, Southern Medical University, \\ Shenzhen, Guangdong, PR China \\ ${ }^{4}$ Master Attending physician, Department of Respiration, Shenzhen Hospital, Southern Medical University, Shenzhen, \\ Guangdong, PR China \\ ${ }^{5}$ Master Chief Physician, Department of Respiration, Shenzhen Hospital, Southern Medical University, Shenzhen, \\ Guangdong, PR China
}

${ }^{\text {\#}}$ These authors contributed equally to this work

\begin{abstract}
Objective: To investigate the clinical value of peripheral serum levels of Surfactant Protein D (SP-D), anti-melanoma differentiation-associated gene 5 (MDA5), Insulation (IL-6) and Tumor Necrosis Factor $(\mathrm{TNF}-\alpha)$ in the prognosis of the degree of Connective Tissue Disease combined with Interstitial Lung Disease (CTD-ILD).

Methods: 339 CTD-ILD patients, 184 CTD patients and 64 healthy volunteers in our hospital from January 2010 to December 2015 were enrolled into the study. The clinical symptoms, the test of High Resolution CT (HRCT) and lung function of all patients were detected and compared between the CTDILD and CTD patients. The serum levels of SP-D, anti-MDA5, IL-6, TNF- $\alpha$ were detected by ELISA among the three groups.

Results: The mean serum levels of SP-D, anti-MDA5, IL-6, TNF- $\alpha$ of CTD-ILD patients and CTD patients were both higher than the control group $(\mathrm{P}<0.05)$; and the mean serum levels of SP-D, antiMDA5, IL-6 of CTD-ILD patients was higher than CTD patients $(P<0.05)$. The mean level of SP-D of CTD-ILD patients with pant was higher than the patients without pant $(P<0.05)$; the mean level of anti MDA5 of CTD-ILD patients with rash was higher than the patients without rash $(P<0.05)$; the mean level of TNF- $\alpha$ of CTD-ILD patients with atony or cough was higher than the patients without atony or cough $(\mathrm{P}<0.05)$. The serum levels of SP-D, anti-MDA5, IL-6, TNF- $\alpha$ in CTD-ILD patients were related to the degree of pulmonary ventilation disorder and pulmonary diffuse dysfunction.

Conclusion: The detection of SP-D, anti-MDA5, IL-6, TNF- $\alpha$ of CTD-ILD patients could be helpful to diagnose the degree of connective tissue disease combined with interstitial lung disease.
\end{abstract}

Keywords: Interstitial lung disease, Connective tissue disease, Surfactant protein D, Anti-melanoma differentiationassociated gene 5, Lung function.

Accepted on October 20, 2017

\section{Introduction}

ILD is different non-tumor, non-infection pulmonary diffuse disease groups during immunopathological process caused by various pathogenic factors. Until now, it is found that about 1000 ILD types in clinic $[1,2]$. CTD belongs to body injury disease caused by abnormal autoimmune system, of which,
ILD is one of common CTD complications, which induce failure of kidney function even death easily $[3,4]$. The onset of CTD-ILD is increasingly gradually, it has no typical clinical indications. So the diagnosis is difficult. Lung biopsy and HRCT are the common method for ILD clinical diagnosis [5]. But trauma of biopsy is big, and the material is limited. Iconography features of HRCT are atypical, easily causing 
misdiagnosis [6]. Therefore, finding specific serum markers have important clinical significance for diagnosing and treating CTD-ILD. This study provides experimental basis for clinical diagnosis and treatment by exploring the differences between pulmonary surface active SP-D, MDA5, IL-6, TNF- $\alpha$ level and normal subjects of serum in CTD-ILD patients and predicting ILD conditions.

\section{Materials and Methods}

\section{Clinical materials}

Ethical approval was given by the medical ethics committee of State Key Laboratory of Respiratory Disease, Guangzhou Institute of Respiratory Health, The First Affiliated Hospital of Guangzhou Medical University with the following reference number: 2013014, CTD-ILD group: This study selected 339 CTD-ILD patients in the international respiratory department and ICU of our hospital from June 2013 to May 2017. All patients were given HRCT examination and X-ray. Complains contain cough, short of breath, dyspnea and so on. There were
156 male patients and 183 female patients. The age was from 26 to $75 \mathrm{y}$ old. The average age was $49.34 \pm 9.62 \mathrm{y}$ old. The course was from 1 to $21 \mathrm{y}$. There were 88 RA-ILD, 73 SLEILD, 52 PM/DM-ILD, 37 SS-ILD, 35 MCTD-ILD, 27Ssc-ILD, 14 AOSD-ILD and 13 SV-ILD. All patients met the corresponding diagnostic criteria by the public.

CTD group without ILD: This study selected 184 CTD patients without ILD in the rheumatic immunity of our hospital from January 2010 to December 2015. There were 78 male patients and 106 female patients. The age was from 22 to $78 \mathrm{y}$ old. The average age was $51.17 \pm 10.43$ y old. The course was from 3 months to $24 \mathrm{y}$. There were 71 RA, 44 SLE, 23 PM/DM, 17 MCTD, 8 Ssc, 3 AOSD and 4 SV. All patients met the corresponding diagnostic criteria by the public.

Normal control group: This study selected 64 healthy volunteers with health examination in outpatients of our hospital from January 2010 to December 2015 as the control group. There were no statistical differences in clinical data of patients between three groups, it had comparability, $\mathrm{P}>0.05$ (Tables 1 and 2).

Table 1. Analysis of general data of admitted subjects.

\begin{tabular}{|c|c|c|c|c|c|c|c|c|}
\hline \multirow[t]{2}{*}{ Group } & \multirow[t]{2}{*}{$\begin{array}{l}\text { Patients } \\
\text { (case) }\end{array}$} & \multirow[t]{2}{*}{ number } & \multirow[t]{2}{*}{ Average age (y old) } & \multicolumn{2}{|c|}{ Sex (case) } & \multirow[t]{2}{*}{$\begin{array}{l}\text { Average } \\
\text { (y) }\end{array}$} & \multirow[t]{2}{*}{$\begin{array}{l}\text { Glucocorticoid } \\
\text { (case) }\end{array}$} & \multirow[t]{2}{*}{$\begin{array}{l}\text { Immunosuppressant } \\
\text { (case) }\end{array}$} \\
\hline & & & & Male & Female & & & \\
\hline The control group & 64 & & $47.82 \pm 10.75$ & 29 & 35 & - & - & - \\
\hline CTD-ILD & 339 & & $49.34 \pm 9.62$ & 156 & 183 & $4.37 \pm 5.16$ & $21(6.19 \%)$ & $30(8.85 \%)$ \\
\hline CTD & 184 & & $51.17 \pm 10.43$ & 78 & 106 & $5.79 \pm 5.52$ & $10(5.43 \%)$ & $13(7.07 \%)$ \\
\hline
\end{tabular}

Table 2. Primary disease classification comparison of patients in two groups (n, \%).

\begin{tabular}{|c|c|c|c|c|c|c|c|c|c|}
\hline Group & $\begin{array}{l}\text { Patients } \\
\text { number }\end{array}$ & RA & SLE & PM/DM & ss & MCTD & Ssc & AOSD & sv \\
\hline CTD-ILD & 339 & $88(25.96)$ & 73 (21.53) & $52(15.34)$ & $37(10.91)$ & $35(10.32)$ & $27(7.96)$ & $14(4.13)$ & $13(3.83)$ \\
\hline CTD & 184 & 71 (38.59) & $44(23.91)$ & $23(12.5)$ & $14(7.61)$ & $17(9.24)$ & $8(4.35)$ & $3(1.63)$ & $4(2.17)$ \\
\hline
\end{tabular}

Inclusive criteria: First, all patients were given chest HRCT examination within three days after admitted into hospital; second, meeting ILD diagnostic criteria; third, patients or their families had signed informed consent form; fourth, this study has approved by ethic committee in our hospital.

Exclusive criteria: First, patients who not met the inclusive criteria above; second, patients with pulmonary infection; third, patients with tuberculosis; fourth, pulmonary lesions caused by environment, physical factor, drug factor and smoking and so on; fifth, patients accompanied with other blood system, alimentary system and malignant tumor; sixth, emotional disorder patients; seventh, patients with obvious abnormal hemotological indexes: WBC less than $4 \times 10^{9} / 1$ or PLT less than $100 \times 10^{9} / 1$.

Pulmonary function examination: Using $\mathrm{FGC}^{+} \mathrm{A}^{+}$type automatic pulmonary function measurement instrument to detect pulmonary function of CTD-ILD patients, including ventilation function and DLCO. Injury degree of lung ventilation can be divided into: slight: FVC from 79 to 60 , FEV1 was from 79 to 60 , FEV1R\% was from 79 to 60 , and MVV was from 79 to 60 . Moderate: FVC was 59 to 50, FEV1 was 59 to $40, \mathrm{FEV} 1 \mathrm{R} \%$ was 59 to 40 , and MVV was 59 to 50. Severe: FVC less than 50, FEV1 less than 40, MVV less than 50. Grading of DLCO injury degree: slight: DLCO was from 89 to $66 \%$. Moderate: DLCO was from 65 to $46 \%$. Severe: DLCO less than $45 \%$.

Iconography examination: Using Toshiba Asteion 4 layer spiral CT to do HRCT scanning. Scanning parameter of HRCT was $135 \mathrm{KV}, 200 \mathrm{~mA}$. They were wheelbase scanning. The thickness of layer was $1 \mathrm{~mm}$. Layer distance was $5 \mathrm{~mm}$. The calculation methods of bone window, do $1 \times 4$ scanning in $1 \mathrm{~cm}$ level over aortic arch, carina and diaphragm. 


\section{Instruments and reagents}

SP-DELISA kits, human anti MDA5 antibody ELISA reagent kits, human IL-6ELISA kits and human TNF- $\alpha$ ELISA kits were bought from Shanghai Jianglai Biotech limited company.

\section{Observation indexes}

Collecting $5 \mathrm{ml}$ peripheral vein blood of all subjects, then put into EDTA anticoagulative tube. According to the operation of ELISA kits to do the specific operation. SP-D, anti MDA5 antibody, IL-6 and TNF-a level in serum of subjects were detected.

\section{Statistical management}

This study used SPSS 21.0 statistical software to do t-test and $\chi^{2}$ test between two groups. Measurement data used paired t- test to compare data between two groups. Enumeration data used $\chi^{2}$ test or Fisher's exact test. $\mathrm{P}<0.05$, there were statistical differences.

\section{Results}

\section{Comparison of SP-D, anti-MDA5 and TNF- $\alpha$ level in serum of patients in two groups}

SP-D, anti-MDA5 antibody, IL-6 and TNF-a level in serum of patients in two groups all higher than subjects in normal control group, there were statistical differences $(\mathrm{P}<0.05)$. In addition, SP-D, anti-MDA5 antibody, IL-6 in serum of patients in CTD-ILD group all higher than CTD patients, there were statistical differences $(\mathrm{P}<0.05)$. There were no obvious differences in TNF- $\alpha$ level of patients in two groups $(\mathrm{P}>0.05$, Table 3).

Table 3. Comparison of SP-D, anti-MDA5 and TNF- $\alpha$ level in serum of patients in three groups $(\bar{x} \pm s)$.

\begin{tabular}{|c|c|c|c|c|}
\hline Group & SP-D (ng/ml) & Anti-MDA5 antibody (ng/ml) & IL-6 (pg/ml) & TNF- $\alpha(p g / m l)$ \\
\hline The control group & $51.27 \pm 23.49$ & 0 & $6.45 \pm 1.18$ & $3.79 \pm 1.15$ \\
\hline CTD-ILD & $102.19 \pm 9.83^{a}$ & $56.53 \pm 13.26^{a}$ & $30.35 \pm 3.73^{a}$ & $12.43 \pm 3.07^{a}$ \\
\hline CTD & $80.41 \pm 8.79^{b c}$ & $24.77 \pm 8.48^{\mathrm{bc}}$ & $16.42 \pm 3.28^{b c}$ & $14.18 \pm 4.22^{\mathrm{b}}$ \\
\hline
\end{tabular}

Note: aCTD-ILD compared with the control group, $\mathrm{P}<0.05$; ${ }^{\mathrm{b}} \mathrm{CTD}$ compared with the control group, $\mathrm{P}<0.05$; ${ }^{\mathrm{c} C T D}$ compared with CTD-ILD, $\mathrm{P}<0.05$

\section{Comparison of SP-D, anti-MDA5 and TNF- $\alpha$ level in serum of patients with different primary disease type of CTD-ILD}

Antibody level of MDA5 antibody in serum of SS-ILD patients was 0 . Anti-MDA5 antibody level in serum of PM/DM-ILD patients was the most high. Anti-MDA5 antibody level in serum of other CTD-ILD patients compared with SS-ILD and PM/DM-ILD patients, there were statistical differences $(\mathrm{P}<0.05)$. There were no statistical differences in SP-D, IL-6 and TNF- $\alpha$ level in serum of patients with different primary disease types of CTD-ILD group $(\mathrm{P}>0.05$, Table 4$)$.

Table 4. Comparison of SP-D, anti-MDA5, IL-6 and TNF- $\alpha$ level in serum of patients with different primary disease type of CTD-ILD $(\bar{x} \pm$ $s)$.

\begin{tabular}{lllll}
\hline Group & SP-D (ng/mI) & $\begin{array}{l}\text { Anti-MDA5 } \\
\text { antibody }(\mathbf{n g} / \mathrm{ml})\end{array}$ & $\mathrm{IL}-6(\mathrm{pg} / \mathrm{ml})$ & $\begin{array}{l}\text { TNF- } \alpha \\
(\mathbf{p g} / \mathrm{ml})\end{array}$ \\
\hline RA-ILD & $\begin{array}{l}83.36 \\
22.53\end{array}$ & $\pm 23.48 \pm 7.55^{\mathrm{de}}$ & $35.41 \pm 4.57$ & $9.18 \pm 1.24$ \\
& 84.09 & $\pm 31.52 \pm 13.03^{\mathrm{de}}$ & $32.87 \pm 5.16$ & $10.06 \pm 1.53$ \\
\hline SLE-ILD & 23.14 & & & \\
\hline PM/DM-ILD & 92.78 & $\pm 72.81 \pm 23.45^{\mathrm{d}}$ & $23.49 \pm 7.25$ & $7.48 \pm 1.58$ \\
& 26.11 & & & \\
\hline SS-ILD & 95.63 & $\pm 0^{\mathrm{e}}$ & $28.85 \pm 4.26$ & $14.29 \pm 1.16$ \\
& 27.75 & & & $10.44 \pm 1.73$ \\
\hline MCTD-ILD & 91.94 & $\pm 27.56 \pm 11.39^{\mathrm{de}}$ & $33.81 \pm 5.97$ & \\
\hline
\end{tabular}

\begin{tabular}{lllll}
\hline Ssc-ILD & 87.72 & $\pm 30.41 \pm 8.65^{\mathrm{de}}$ & $25.46 \pm 5.73$ & $14.25 \pm 2.46$ \\
& 22.59 & & & \\
\hline AOSD-ILD & 89.48 & $\pm 36.49 \pm 12.63^{\mathrm{de}}$ & $28.38 \pm 6.27$ & $10.85 \pm 0.92$ \\
& 26.65 & & & \\
\hline SV-ILD & 97.51 & $\pm 33.75 \pm 10.74^{\mathrm{de}}$ & $31.89 \pm 6.02$ & $14.01 \pm 1.01$ \\
& 20.74 & & & \\
\hline
\end{tabular}

Note: ${ }^{d}$ Compared with SS-ILD patients, $P<0.05$.

The relations between SP-D, anti-MDA5, IL-6, TNF- $\alpha$ level in serum of CTD-ILD patients and clinical manifestations

According to the main clinical manifestations of CTD-ILD, it can be divided group whether had rash, group whether had fatigue, group whether had cough, group whether had short of breath, group whether had chest pain, group whether had Raynaud phenomenon.

According to detection results showed that SP-D level in serum of patients without short of breath lower than patients with short of breath there were statistical differences $(\mathrm{P}<0.05)$. AntiMDA5 antibody level in serum of patients without rash lower than patients with rash, there were statistical differences $(\mathrm{P}<0.05)$. TNF- $\alpha$ level in serum of patients without fatigue and cough lower than patients with fatigue and cough, there were statistical differences $(\mathrm{P}<0.05)$. SP-D, anti-MDA5, IL-6, TNF$\alpha$ level in serum of other clinical symptoms in negative subgroup and positive subgroup were similar, there were no statistical differences $(\mathrm{P}>0.05$, Table 5$)$. 


\section{Comparison of SP-D, anti-MDA5, IL-6, TNF- $\alpha$ level in serum of CTD-ILD patients of different iconography and lung function}

According to different manifestations of HRCT iconography results of CTD-ILD patients, they can be divided into ground glass opacity subgroup (187 cases) and honeycomb opacity subgroup (152 cases).

For patients with normal or slight disorder ventilation, IL-6 and TNF- $\alpha$ in serum of patients in ground glass opacity subgroup compared with honeycomb opacity subgroup, there were statistical differences $(\mathrm{P}<0.05)$. For patients with moderate and severe disorder ventilation, SP-D and anti-MDA5 in serum of patients in ground glass opacity subgroup compared with honeycomb opacity subgroup, there were statistical differences $(\mathrm{P}<0.05)$. In addition, for patients with honeycomb opacity, SP$\mathrm{D}$ and IL-6 in serum of patients with moderate and severe disorder ventilation compared with patients with normal or slight disorder ventilation, there were statistical differences $(\mathrm{P}<0.05$, Table 6).

For patients with normal or slight diffuse function disorder, SP$\mathrm{D}$ level in serum of patients in ground glass opacity subgroup higher than honeycomb opacity subgroup, there were statistical differences $(\mathrm{P}<0.05)$. For patients with moderate or severe diffuse function disorder, anti-MDA5 antibody in serum of patients in ground glass opacity subgroup higher than honeycomb opacity subgroup, there were statistical differences $(\mathrm{P}<0.05)$. In addition, for patients with ground glass opacity, SP-D level in serum of patients with moderate or severe diffuse function disorder lower than normal or slight disorder patients, there were statistical differences $(\mathrm{P}<0.05)$. For patients with honeycomb opacity, anti-MDA5 antibody in serum of patients in moderate or severe diffuse function disorder lower than patients with normal or slight diffuse function disorder, there were statistical differences $(\mathrm{P}<0.05$, Table 7$)$.

Table 5. The relations between $S P-D$, anti-MDA5, IL-6, TNF- $\alpha$ level in serum of CTD-ILD patients and clinical manifestations $(\bar{x} \pm s)$.

\begin{tabular}{|c|c|c|c|c|c|c|}
\hline Clinical features & & Patients number & SP-D (ng/ml) & A nti-MDA5antibody (ng/ml) & IL-6 (pg/ml) & TNF- $\alpha(p g / m l)$ \\
\hline \multirow[t]{2}{*}{ Rash } & Yes & 85 & $84.16 \pm 21.79$ & $69.16 \pm 9.47$ & $33.84 \pm 6.78$ & $12.37 \pm 1.24$ \\
\hline & No & 254 & $87.34 \pm 23.25$ & $43.81 \pm 7.32^{f}$ & $29.45 \pm 7.86$ & $11.49 \pm 1.58$ \\
\hline \multirow[t]{2}{*}{ Fatigue } & Yes & 241 & $88.78 \pm 21.54$ & $54.33 \pm 9.96$ & $32.87 \pm 6.73$ & $14.25 \pm 1.21$ \\
\hline & No & 98 & $89.12 \pm 25.47$ & $52.84 \pm 8.27$ & $33.62 \pm 7.16$ & $7.68 \pm 0.84^{f}$ \\
\hline \multirow[t]{2}{*}{ Cough } & Yes & 171 & $86.57 \pm 23.19$ & $59.39 \pm 7.54$ & $30.76 \pm 8.59$ & $14.19 \pm 1.01$ \\
\hline & No & 168 & $92.51 \pm 20.46$ & $60.82 \pm 9.31$ & $23.91 \pm 9.07$ & $10.47 \pm 0.75^{f}$ \\
\hline \multirow[t]{2}{*}{ Short of breath } & Yes & 193 & $98.62 \pm 27.75$ & $62.77 \pm 8.41$ & $28.63 \pm 5.42$ & $12.47 \pm 1.76$ \\
\hline & No & 146 & $74.49 \pm 22.23^{f}$ & $59.76 \pm 8.83$ & $30.27 \pm 6.57$ & $10.29 \pm 1.19$ \\
\hline \multirow[t]{2}{*}{ Chest pain } & Yes & 126 & $91.94 \pm 25.08$ & $60.18 \pm 11.26$ & $36.44 \pm 8.93$ & $10.31 \pm 1.42$ \\
\hline & No & 213 & $95.32 \pm 27.78$ & $60.17 \pm 7.49$ & $30.45 \pm 6.62$ & $8.75 \pm 0.67$ \\
\hline \multirow{2}{*}{$\begin{array}{l}\text { Raynaud } \\
\text { phenomenon }\end{array}$} & Yes & 82 & $90.71 \pm 20.43$ & $64.54 \pm 10.38$ & $29.95 \pm 8.98$ & $12.13 \pm 1.35$ \\
\hline & No & 257 & $91.34 \pm 19.87$ & $7.48 \pm 9.79$ & $31.26 \pm 9.31$ & $11.26 \pm 1.38$ \\
\hline
\end{tabular}

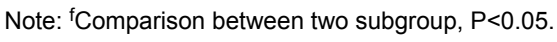

Table 6. Comparison of SP-D, anti-MDA5, IL-6, TNF-a level in serum of CTD-ILD patients of different iconography and lung function ( $\bar{x} \pm$ S).

\begin{tabular}{|c|c|c|c|c|c|c|}
\hline $\begin{array}{l}\text { Ventilation } \\
\text { function }\end{array}$ & HRCT & $\mathbf{n}$ & SP-D (ng/ml) & $\begin{array}{l}\text { Anti-MDA5 } \\
\text { (ng/ml) }\end{array}$ & antibody IL-6 (pg/ml) & TNF- $\alpha(p g / m l)$ \\
\hline \multirow[t]{2}{*}{ Normal or slight } & Ground glass opacity & 122 & $101.32 \pm 21.74$ & $23.59 \pm 7.26$ & $28.79 \pm 3.15$ & $8.76 \pm 0.87$ \\
\hline & Honey comb opacity & 103 & $99.86 \pm 24.33$ & $28.63 \pm 10.52$ & $18.48 \pm 3.99^{f}$ & $12.34 \pm 1.25^{f}$ \\
\hline \multirow[t]{2}{*}{ Moderate or severe } & Ground glass opacity & 65 & $93.52 \pm 20.68$ & $36.71 \pm 7.14$ & $31.26 \pm 5.03$ & $12.73 \pm 0.96$ \\
\hline & Honey comb opacity & 49 & $81.75 \pm 17.26^{\mathrm{fg}}$ & $22.86 \pm 11.63^{f}$ & $29.85 \pm 4.11 \mathrm{~g}$ & $10.84 \pm 1.05$ \\
\hline
\end{tabular}

Note: ${ }^{\mathrm{f} C}$ Comparison of ventilation function between two subgroups, $\mathrm{P}<0.05$; comparison of gHRCT between two subgroups, $\mathrm{P}<0.05$. 
Study on difference of peripheral serum SP-D, anti-MDA5, IL-6 and TNF- $\alpha$ in CTD-ILD patients.

Table 7. Comparison of SP-D, anti-MDA5, IL-6, TNF-a level in serum of CTD-ILD patients of different iconography and lung function $(\bar{x} \pm s)$.

\begin{tabular}{|c|c|c|c|c|c|c|c|}
\hline $\begin{array}{l}\text { Diffusion } \\
\text { function }\end{array}$ & HRCT & $\mathbf{n}$ & SP-D (ng/ml) & $\begin{array}{l}\text { Anti-MDA5 } \\
\text { (ng/ml) }\end{array}$ & antibody & IL-6 (pg/ml) & TNF- $\alpha(p g / m l)$ \\
\hline \multirow[t]{2}{*}{ Normal or slight } & Ground glass opacity & 138 & $102.47 \pm 21.65$ & $27.73 \pm 7.46$ & & $26.41 \pm 4.23$ & $9.77 \pm 1.31$ \\
\hline & Honey comb opacity & 117 & $87.32 \pm 22.89^{f}$ & $28.45 \pm 9.68$ & & $25.44 \pm 3.86$ & $10.84 \pm 0.98$ \\
\hline \multirow{2}{*}{$\begin{array}{l}\text { Moderate } \\
\text { severe }\end{array}$} & Ground glass opacity & 49 & $92.83 \pm 21.75^{g}$ & $35.86 \pm 7.29$ & & $30.20 \pm 5.49$ & $12.54 \pm 1.17$ \\
\hline & Honey comb opacity & 35 & $91.42 \pm 24.12$ & $16.24 \pm 5.35 f^{9}$ & & $26.83 \pm 4.27$ & $13.57 \pm 1.06$ \\
\hline
\end{tabular}

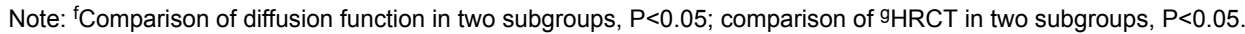

\section{Discussion}

CTD is the common autoimmune system diseases in clinic at present, it mainly injuries connective tissue and vessels of whole body, such as pulmonary interstitial disease [7]. The main indications of CTD-ILD are inflammation and fibrosis in lung. The pathogenesis was unclear. It was usually in female patients [8]. This study selects 339 patients in respiratory department of our hospital. Female patients account for $53.98 \%$. Because of different primary diseases of CTD-ILD, pathological manifestations of patients are multiple, RA, SLE and $\mathrm{PM} / \mathrm{DM}$ are common [9]. In recent years, with the wide application of HRCT and lung function examination, diagnosis rate of CTD-ILD increases significantly. But there are still a certain error diagnosis and omission diagnosis [10,11]. Therefore, exploring serum markers of CTD-ILD patients has significant effects for diagnosing and predicting conditions.

SP-D protein was synthesized and expressed by epithelial cells of end in alimentary tract, it has close relations with lung fibrosis, which can lower tension of alveolar surface, participate immune reaction of lung [12]. In this study, SP-D level of CTD-ILD patients and CTD patients higher than normal level obviously. SP-D level of CTD-ILD patients higher than CTD patients, there are statistical differences $(\mathrm{P}<0.05)$. It shows SP-D level has positive correlations with degree of lung injuries. Except short of breath, the influences of various clinical manifestations of patients on SP-D level changes are not obvious, it also shows that SP-D has relations with lung injuries indirectly. For patients with moderate and severe disorder ventilation and with normal or slight disorder ventilation, SP-D level in serum of patients with honeycomb opacity lower than ground glass opacity patients, it shows SP$\mathrm{D}$ may participate occurrence of early pulmonary alveoli inflammation.

Anti-MDA5 antibody belongs to viral sensor in cells, it can identify RNA virus quickly, launch immune response of body [13-15]. In this study, anti-MDA5 antibody level in serum of CTD-ILD patients and CTD patients higher than normal level obviously, and anti-MDA5 antibody level of CTD-ILD patients higher than CTD patients, there are statistical differences $(\mathrm{P}<0.05)$. Anti-MDA5 antibody level in serum of PM/DM-ILD patients higher than other CTD-ILD patients obviously, and it has close relations with symptoms of rash. In addition, in this study, anti-MDA5 antibody level in ground glass opacity patients higher than honeycomb opacity patients. It is similar to SP-D. Anti-MDA5 antibody may participate for the occurrence of early pulmonary alveolar inflammation, which can be serum markers detection of CTD-ILD onset in early stage.

IL-6 is small-molecular glycopeptides secreted by activated T lymph cells. There are studies shows that IL-6 has close relations with fibrosis of pulmonary interstitium [16,17]. In this study, IL-6 level in serum of CTD-ILD and CTD patients higher than normal level obviously, IL-6 level of CTD-ILD patients higher than CTD patients $(\mathrm{P}<0.05)$. Furthermore, for patients with normal and slight disorder ventilation, IL-6 level in serum of honeycomb opacity patients lower than ground glass opacity patients, it shows IL-6 plays an important function in early stage of alveolar inflammation even stage of pulmonary fibrosis.

TNF- $\alpha$ is an inflammatory cell factor secreted by mononuclear phagocyte, it can promote inflammatory reactions of phagocyte combined with IL-6 [18,19]. In this study, TNF- $\alpha$ level in serum of CTD-ILD and CTD patients higher than the control group, but there are no statistical differences between them. It shows TNF- $\alpha$ hasn't specificity for judging whether CTD patients combined with ILD. In addition, clinical symptoms of fatigue, cough etc. have close relations with TNF- $\alpha$ level. For patients with normal or slight disorder ventilation, TNF- $\alpha$ level in serum of honeycomb opacity patients higher than ground glass opacity patients, it shows that TNF- $\alpha$ participates the process of pulmonary fibrosis.

In conclusion, SP-D and anti-MDA5 antibody can be the early detection index of CTD-ILD patients. IL- 6 and TNF- $\alpha$ can be the detection index for pulmonary fibrosis, which has significant clinical guide for judging and predicting CTD-ILD conditions, and provides experimental basis for clinical treatment methods selection.

\section{References}

1. Urisman A, Jones KD. Pulmonary pathology in connective tissue disease. Semin Respir Crit Care Med 2014; 35: 201-212.

2. Zhou MY. Analysis of clinical features of connective tissue disorder related interstitial lung disease. China Foreign Med Treat 2017; 42: 68-70.

3. Zang LL. Study on application value of high-resolution CT in diagnosing infantile chronic pulmonary interstitium lesions. Contemp Med Forum 2017; 15: 136-137.

4. Jee AS, Adelstein S, Bleasel J. Role of autoantibodies in the diagnosis of connective-tissue disease ILD (CTD-ILD) 
and interstitial pneumonia with autoimmune features (IPAF). J Clin Med 2017; 6: 51.

5. Adegunsoye A, Oldham JM, Valenzi E. Interstitial pneumonia with autoimmune features: value of histopathology. Arch Pathol Lab Med 2017; 141: 960-969.

6. Ren Y, Zhu P. The effects of inflammatory cells and cellular factors in inflammation and fibrosis of interstitial pulmonary diseases. Chinese J Cell Mol Immunol 2011; 27: 1272-1274.

7. Baldi BG, Carvalho CRR, Dias OM. Diffuse cystic lung diseases: differential diagnosis. J Bras Pneumol 2017; 43: 140-149.

8. Khanna D, Mittoo S, Aggarwal R. Connective tissue disease-associated interstitial lung diseases (CTD-ILD)report from OMERACTCTD-ILD working group. J Rheumatol 2015; 42: 2168-2171.

9. Toyoda Y, Hanibuchi M, Kishi J. Clinical features and outcome of acute exacerbation of interstitial pneumonia associated with connective tissue disease. J Med Invest 2016; 63: 294-299.

10. Liang ZQ, Jiang FY, Zhao L. Clinical value of HRCT combined with pulmonary function examination in the diagnosis of connective tissue disease-related pulmonary interstitial lesions. Hebei Med 2017; 23: 594-597.

11. Han Q, Luo Q, Chen X. The evaluation of clinical usefulness of transbrochoscopic lung biopsy in undefined interstitial lung diseases: a retrospective study. Clin Respir J 2017; 11: 168-175.

12. Bonella F, Costabel U. Biomarkers in connective tissue disease-associated interstitial lung disease. Semin Respir Crit Care Med 2014; 35: 181-200.

13. Uchikawa E, Lethier M, Malet H. Structural analysis of dsRNA binding to anti-viral pattern recognition receptors LGP2 and MDA5. Mol Cell 2016; 62: 586-602.
14. Herault M, Marie C, Plantamura E, Poeck H. Methods and pharmaceutical compositions for the treatment of allergic contact dermatitis. Pat WO2015144714 2015.

15. Fullam A, Schoder M. DExD/H-box RNA helicases as mediators of anti-viral innate immunity and essential host factors for viral replication. Biochimica et Biophysica Acta 2013; 1829: 854.

16. Liu M, Zeng $\mathrm{X}$, Wang J. Immunomodulation by mesenchymal stem cells in treating human autoimmune disease-associated lung fibrosis. Stem Cell Res Ther 2016; 7: 63-78.

17. Wolff Z, Malemud C J. Controversies in the use of mesenchymal stem cells for treating autoimmune diseases. Mesenchym Stem Cells Immunomodul 2016.

18. Świdrowska J, Zygmunt A, Biernacka-Zielinska M. Influence of biologic therapy on growth in children with chronic inflammatory connective tissue diseases. Reumatologia 2015; 53: 14-20.

19. Bruzzese V, Zullo A, Piacchianti D A. Vitamin D deficiency in patients with either rheumatic diseases or inflammatory bowel diseases on biologic therapy. Int Emerg Med 2016; 11: 803-807.

\section{*Correspondence to}

Dandan Zhang

Master Chief Physician

Department of Respiration

Shenzhen Hospital

Southern Medical University

PR China 